\title{
Metformin Transport Rates Between Plasma and Red Blood Cells in Humans
}

\author{
Janis Kurlovics ${ }^{1,2} \cdot$ Darta Maija Zake $^{1,3} \cdot$ Linda Zaharenko $^{3} \cdot$ Kristaps Berzins $^{1} \cdot$ Janis Klovins $^{3} \cdot$ Egils Stalidzans $^{1,3}$
}

Accepted: 8 July 2021 / Published online: 26 July 2021

(c) The Author(s) 2021

\begin{abstract}
Background Metformin has been used for the treatment of type 2 diabetes for over 60 years; however, its mechanism of pharmacological action is not fully clear. Different hypotheses exist regarding metformin distribution and redistribution mechanisms between plasma and erythrocytes/red blood cells (RBCs).

Objective We aimed to test the hypothesis that the metformin distribution between plasma and RBC occurs via concentration difference-driven passive transport and estimated transport rate coefficient values based on metformin concentration time series in plasma and RBCs from in vivo studies.

Methods An ordinary differential equation (ODE) system with two compartments was used to describe diffusion-based passive transport between plasma and RBCs. Metformin concentration time series in plasma and RBCs of 35 individuals were used for metformin transport parametrization. Plasma concentration has been approximated by biexponential decline. Results A single passive transport coefficient, $k=0.044 \pm 0.014\left(\mathrm{~h}^{-1}\right)$, can be applied, describing the uptake and release transport rate versus the linear equation $v=k \times\left(M_{\mathrm{pl}}-M_{\mathrm{RBC}}\right)$, where $M_{\mathrm{pl}}$ is the metformin concentration in plasma and $\mathrm{M}_{\mathrm{RBC}}$ is the metformin concentration in RBCs.

Conclusions Our research suggests that passive transport can explain metformin distribution dynamics between plasma and RBCs because transport speed is proportional to the metformin concentration difference and independent of the transport direction. Concentration difference-driven passive transport can explain the mechanism of faster metformin distribution to RBCs the first few hours after administration, and faster release and domination of the redistribution transport rate after metformin concentration in plasma becomes smaller than in RBCs.
\end{abstract}

Janis Kurlovics

janis.kurlovics@lu.lv

1 Computational Systems Biology Group, Institute of Microbiology and Biotechnology, University of Latvia, Riga, Latvia

2 Division of Pharmaceutical Chemistry and Technology, University of Helsinki, Helsinki, Finland

3 Latvian Biomedical Research and Study Centre, Riga, Latvia

\section{Key Points}

The objective was to evaluate the metformin distribution mechanisms between plasma and RBC by mathematical modeling and estimate transport rate coefficient based on in vivo metformin concentration time-series in human plasma and RBC.

The partitioning and repartitioning between $\mathrm{RBC}$ and plasma is modelled as passive transport with the same transport rate coefficient describing influx and outflux, supporting the assumption of diffusion being the main process ensuring metformin transportation between these compartments. 


\section{Introduction}

Metformin is a first-line oral antidiabetic medication that has been widely used to treat type 2 diabetes for over 60 years. Despite the long clinical experience, its pharmacological mechanisms of action are not fully understood. The mechanisms underlying metformin action appear to be complex and involve both insulin-sensitive and noninsulin-sensitive tissues. While the most classical effect of metformin is the reduction of hyperglycemia by inhibition of hepatic gluconeogenesis, the contribution of mechanisms in other tissues, such as an increase in glucose uptake in skeletal muscle, increase in insulin sensitivity in adipose tissue, and glucose utilization in gut enterocytes, have been demonstrated [1].

Metformin is a small molecule (molecular weight $165 \mathrm{Da}$ ) that is not metabolized and is highly hydrophilic. It is of a basic nature and, under physiological $\mathrm{pH}$, is almost fully ionized. Metformin also has negligible protein binding [2]; however, it has a comparably high volume of distribution, i.e. above $200 \mathrm{~L}$ after a single oral dose [3]. Metformin is known to be transported across cellular membranes by using active transporters, i.e. PMAT, OCT1, OCT2, OCT3, and MATE1 [4], that explain the observed distribution volume. It is rapidly excreted in urine, with plasma elimination ranging from 2 to $6 \mathrm{~h}$. Nonetheless, terminal elimination of the drug is slow, with a fraction of $<5 \%$ being eliminated and with a half-life of between 9 and $17 \mathrm{~h}$ [5], suggesting the existence of a deep compartment [6]. The published data suggest that metformin accumulates in a deep compartment formed of red blood cells (RBCs) [7, 8] and a deep tissue compartment, most likely gastrointestinal tissues $[9,10]$.

Given the hydrophilic nature of metformin, it has been assumed that it cannot cross the phospholipid bilayer via diffusion [4]. At the same time, metformin enters the RBC where relevant transporters are not expressed, suggesting a marginal transport via diffusion $[7,8,11,12]$. The maximal metformin concentration in RBCs is reached later than in plasma and is considerably lower [8], confirming that the transport to RBCs is not intensive. The measurement of metformin concentrations in major deep compartments of metformin action is clinically unavailable and is currently predicted by some mathematical models [13-15].

$\mathrm{RBCs}$ could be used to gain insight into metformin distribution and accumulation in the rest of the body in cases of chronic metformin therapy, as the terminal half-life of metformin in plasma and urine is very similar to the terminal halflife in RBCs [7, 8]. Metformin has a direct pharmacodynamic effect on RBCs in patients with type 2 diabetes as it increases noninsulin-dependent glucose uptake and storage of glycogen under conditions of hyperglycemia [16].

An interesting pharmacokinetic-related peculiarity of RBCs is that plasma is the only metformin carrier interacting with
RBCs, both in uptake and release, and the concentrations in both plasma and RBCs are experimentally determined in vivo. The absence of transport proteins in RBC membranes enables assessment of the transport without proteins in vivo. This also allows estimation of the membrane transport impact in other tissues. Various authors have described the pharmacokinetic parameters of metformin distribution in RBCs [7, 8, 12]. A few in vitro and in vivo studies have aimed to describe the metformin distribution between plasma and RBCs [7, 8, 12, 17, 18]; however, based on our knowledge, a mechanistic modelbased [19] estimation of the metformin transport mechanism and its parameters based on in vivo data has not been carried out.

Considering that no active transporters are expressed in RBCs, and plasma membrane permeability should be equal in both directions, we hypothesized that concentration difference-driven passive transport can explain the distribution of metformin between plasma and RBCs. Mechanistic mathematical models with diffusion-based passive transport kinetic equations have been built and parametrized using metformin concentration time series in plasma and RBCs from in vivo studies.

\section{Materials and Methods}

\subsection{Experimental Data}

Metformin concentration-time courses in plasma and RBCs were used [20-22] following a single peroral $500 \mathrm{mg}$ dose of metformin, administered under fed conditions. Thirty-five nondiabetic volunteers were included in this study (Table 1). All participants signed informed consent and the study was approved by the institutional Ethics Committee (PSCUH, Nr. 3000610-18L). To be eligible for this study, subjects confirmed they were not using any medications other than vitamins. The liver enzyme levels of participants (alanine aminotransferase, g-glutamyltransferase) were less than double the respective normal value, and no participants had renal failure (mean serum creatinine $75.6 \pm 13.8 \mathrm{mmol} / \mathrm{L}$ ). Before inclusion in this study, women were asked to provide a urine sample to confirm a negative pregnancy test. Venous blood samples were taken just prior to administration and

Table 1 Characteristics of study participants

\begin{tabular}{ll}
\hline Male $[n(\%)]$ & $15(42.8)$ \\
Female $[n(\%)]$ & $20(57.2)$ \\
Mean age $\pm \mathrm{SD}$, years & $26.71 \pm 5.97$ \\
Mean BMI $\pm \mathrm{SD}, \mathrm{kg} / \mathrm{m}^{2}$ & $23.61 \pm 3.64$ \\
Mean serum creatinine $\pm \mathrm{SD}, \mathrm{mmol} / \mathrm{L}$ & $75.65 \pm 13.81$ \\
\hline
\end{tabular}

$B M I$ body mass index, $S D$ standard deviation 
at $1,2,3,6,10$, and $24 \mathrm{~h}$ postdose. Metformin concentration time series in plasma, and RBCs of the 35 nondiabetic individuals (Online Resource 1) were used for metformin transport parametrization.

\subsection{Mathematical Model}

A mathematical model was built to test the hypothesis regarding passive transport determining the distribution and redistribution of metformin between plasma and RBCs. Diffusion-based passive transport occurs by random processes through the lipid bilayer membrane from the side with the larger concentration to the side with the lower concentration, and can switch when the concentration proportion changes to the opposite [23]. The driving force of diffusion (simple or facilitated) is the concentration difference (transmembrane concentration gradient), tending to equalize the concentration of molecules on both sides of the membrane [24]. It is essential that the rate of diffusion is directly and linearly proportional to the concentration difference.

The proposed model is based on Fick's Law of diffusion, which describes the time course of the transfer of a solute between two compartments that are separated by a membrane [25]. The rate of diffusion-based passive transport from plasma to RBCs $\left(v_{\text {in }}\right)$ and the rate from RBCs to plasma $\left(v_{\text {out }}\right)$ can be calculated as shown in Eqs. 1 and 2 [24]:

$v_{\text {in }}=\frac{D \times a \times P \times M_{\mathrm{pl}}}{m}$,

and

$v_{\text {out }}=\frac{D \times a \times P \times M_{\mathrm{RBC}}}{m}$,

where $D$ is the diffusion coefficient, $a$ is the membrane area, $P$ is the lipid/water partition coefficient of metformin, $M$ is the membrane thickness, $M_{\mathrm{pl}}$ is the metformin concentration in plasma, and $M_{\mathrm{RBC}}$ is the metformin concentration in RBCs.

In the proposed model, the constants in Eqs. 1 and 2, i.e. diffusion coefficient $(D)$, membrane area $(a)$, lipid/water partition coefficient $(P)$, and membrane thickness $(m)$, are expressed by the diffusion transport rate coefficient $k$ :

$k=\frac{D \times a \times P}{m}$.

In the model, we assume that independent transport rate coefficients may be needed to describe uptake $\left(k_{\text {in }}\right)$ and release $\left(k_{\text {out }}\right)$ of metformin, and we therefore implemented transport rate equations in the model as follows (Eqs. 4 and $5)$ :

$v_{\text {in }}=k_{\text {in }} \times M_{\mathrm{pl}}$,

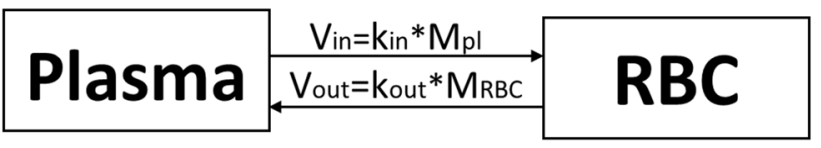

Fig. 1 Two-compartment model of metformin transport between plasma and RBCs with absorption $\left(v_{\text {in }}\right)$ and release $\left(v_{\text {out }}\right)$ fluxes. $k_{\text {in }}$ transport rate coefficient to RBCs from plasma $\left(\mathrm{h}^{-1}\right), k_{\text {out }}$ transport rate coefficient from $\mathrm{RBCs}$ to plasma $\left(\mathrm{h}^{-1}\right), M_{p l}$ metformin concentration in plasma $(\mathrm{ng} / \mathrm{mL}), M_{R B C}$ metformin concentration in RBCs (ng/ $\mathrm{mL}), R B C$ red blood cells

and

$v_{\text {out }}=k_{\text {out }} \times M_{\mathrm{RBC}} \cdot s$

A special case where $k=k_{\text {in }}=k_{\text {out }}$ was applied in the modeling experiments to test whether a single diffusion transport rate coefficient can explain experimental results. The summary transport rate, versus including transport in both directions, can then be expressed as follows (Eq. 6):

$v=k \times\left(M_{\mathrm{pl}}-M_{\mathrm{RBC}}\right)$.

The mathematical model utilizes the fact that RBCs can exchange metformin with plasma only and that metformin concentrations in both compartments are measured. The transport between plasma and RBCs is described as a twocompartment model (Fig. 1) [26].

The metformin concentration in plasma $\left(M_{\mathrm{pl}}\right)$ is approximated by a biexponential decline (Eq. 7) [27]:

$M_{\mathrm{pl}}=A \times e^{-c \times t}-B \times e^{-d \times t}$,

where $A$ is the $y$-intercept of the distribution curve, $c$ is the first-order distribution rate constant, $B$ is the $y$-intercept of the elimination curve, $d$ is the first-order elimination rate constant, and $t$ represents time.

In the model, we introduced $A=B$ to ensure that the plasma concentration approximation function has 0 value when the metformin dose has been received at $t=0$. The metformin concentration in $\mathrm{RBCs}\left(M_{\mathrm{RBC}}\right)$ is a dependent variable determined by reactions. The values of diffusion coefficients and biexponential decline parameters are identified by parameter estimation fitting model simulations to the experimental data.

An ordinary differential equation (ODE) system was used to describe the diffusion-based passive transport rate between plasma and RBCs using the two rate equations (4) and (5). Two models for each of the 35 patients have been developed and parametrized during parameter estimation: (1) independent transport coefficients $\left(k_{\text {in }}\right.$ and $\left.k_{\text {out }}\right)$ for uptake and release; and (2) single coefficient $k$ used for transport in both directions (uptake and release coefficients are equal). 
The volume of the RBC compartments was fixed in the model for all 35 individuals, at a value corresponding to a body weight of $70 \mathrm{~kg}$ for humans, with $2198 \mathrm{~mL}$ of RBCs [28]. The size of the plasma compartment was not defined because the plasma concentration was fixed by biexponential decline (Eq. 7) and approximation of experimental data. Time to reach maximum concentration $\left(T_{\max }\right)$ and maximum concentration $\left(C_{\max }\right)$ values were determined from model simulations.

COPASI software [29] was used for mathematical modeling and parameter estimation. The fitness of experimental data with model simulations was measured using the mean square error (MSE) value calculated by COPASI. ConvAn [30] was used to select the most appropriate optimization method, and a modification of the COPASI wrapper SpaceScanner [31] was applied for parallel optimization runs. Sample models describing the average experimental curve with a single (Biomodels ID: MODEL2103170001) and independent (Biomodels ID: MODEL2103170002) diffusion transport rate coefficient in COPASI format (Online Resource 2) and SBML format (Online Resource 3) were deposited in the BioModels database [32].

\section{Results}

\subsection{Single Diffusion Transport Rate Coefficient $k$-Value versus the Independent $k_{\text {in }}$ and $k_{\text {out }}$}

Parameter estimations to match the model simulations with experimental results were performed using (1) independent $k_{\text {in }}$ and $k_{\text {out }}$ values, and (2) a single coefficient $K$ (corresponds to $k=k_{\text {in }}=k_{\text {out }}$ ). Both cases were applied to the metformin concentration-time courses, and on the average time course, of 35 individuals.

The single transport rate coefficient of the average concentration-time course data from 35 experimental measurements was $k_{\text {ave }}=0.044 \mathrm{~h}^{-1}$ (Fig. 2a), which is equal to the average value of all individual single coefficients $\left(k=0.044 \pm 0.014 \mathrm{~h}^{-1}\right)$. Furthermore, the estimated independent transport rate coefficients for the average curve were $k_{\text {in/ave }}=0.044 \mathrm{~h}^{-1}$ and $k_{\text {out } / \text { ave }}=0.039 \mathrm{~h}^{-1}$ (Fig. 2b). At the same time, the average values of the estimated transport rate coefficients for individuals were $k_{\text {in }}=0.044 \pm 0.012 \mathrm{~h}^{-1}$ and $k_{\text {out }}=0.043 \pm 0.013 \mathrm{~h}^{-1}$ (Online Resource 4). Figure 2 demonstrates that a single coefficient can describe experimental results equally well compared with two independent coefficients.

The estimated coefficients for individual curves are highly variable between individuals (Fig. 3), reflecting the known high variability of metformin pharmacokinetics among individuals. In our experimental data (see Online Resource 1), there are big differences in individual concentration-time course data for the metformin concentrations in plasma and RBCs. The coefficients of individuals have a wide $k_{\text {in }} / k_{\text {out }}$ ratio (ranging from 0.45 to 2.56 ). In 14 cases, $k_{\text {out }}$ is larger than $\mathrm{k}_{\mathrm{in}}$, and, in 21 cases, it is the opposite, while their average values are very similar (0.044 and 0.043). Remarkably, individuals' $k$-values (Fig. 3) were larger than $k_{\text {in }}$ if $k_{\text {in }}>k_{\text {out }}$, and smaller than $k_{\text {in }}$ if $k_{\text {in }}<k_{\text {out }}$. In other words, $k_{\text {in }}$ values were between $k_{\text {out }}$ and $k$-values in all cases except for one individual (No. 19 in Fig. 3). There was a very high correlation (0.99) between $k$ and $k_{\text {in, }}$ while the $k$ correlation with $k_{\text {out }}$ was smaller and negative

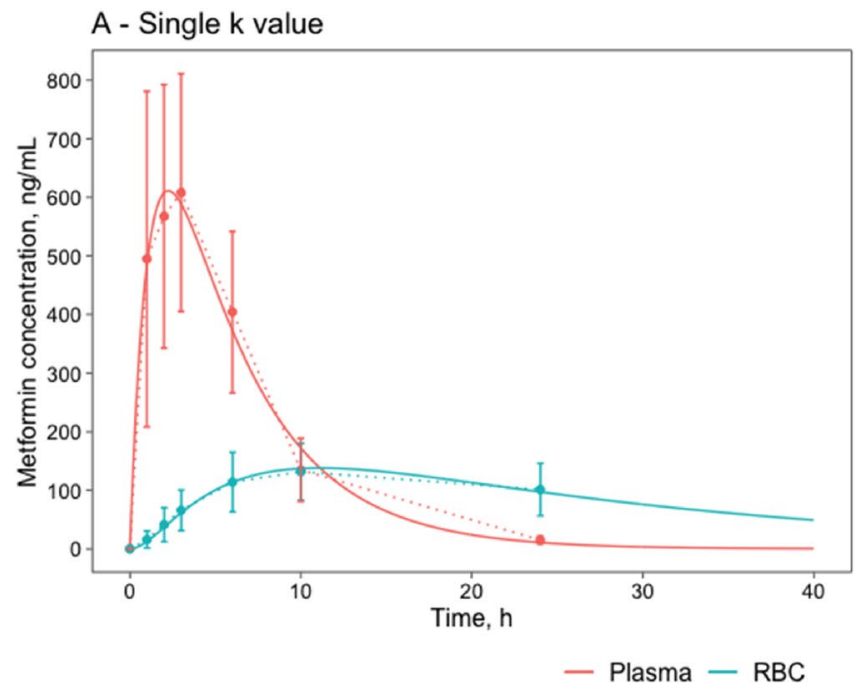

Fig. 2 Parameter estimation results of the average curve. Dots show experimental values while lines represent the model simulation. a Single $k$-value $\left(k_{\text {ave }}=0.044 \mathrm{~h}^{-1}\right.$, mean square error $\left.=286\right)$; and $\mathbf{b}$
$B$ - Independent $k_{\text {in }} k_{\text {out }}$ values

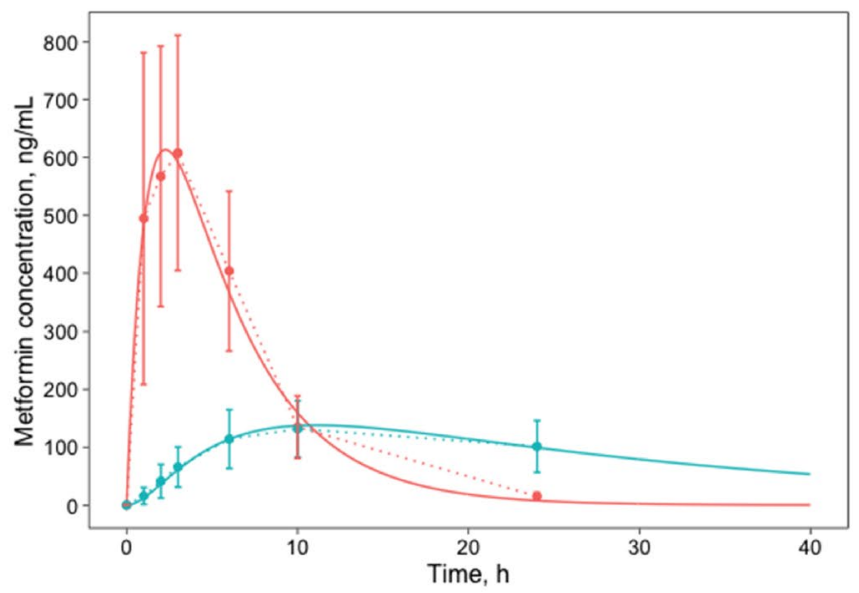

... Measured - Model fit mean square error $=273)$. $R B C s$ red blood cells 
Fig. 3 Diffusion coefficient $k$, $k_{\text {in }}$ and $k_{\text {out }}$ values per individual (average values are represented by lines). The average values of $k$ and $k_{\text {in }}$ were identical.

Fig. $4 T_{\max }$ and $C_{\max }$ of individual plasma curves. $T_{\max }$ time to reach maximum concentration, $C_{\text {max }}$ maximum concentration

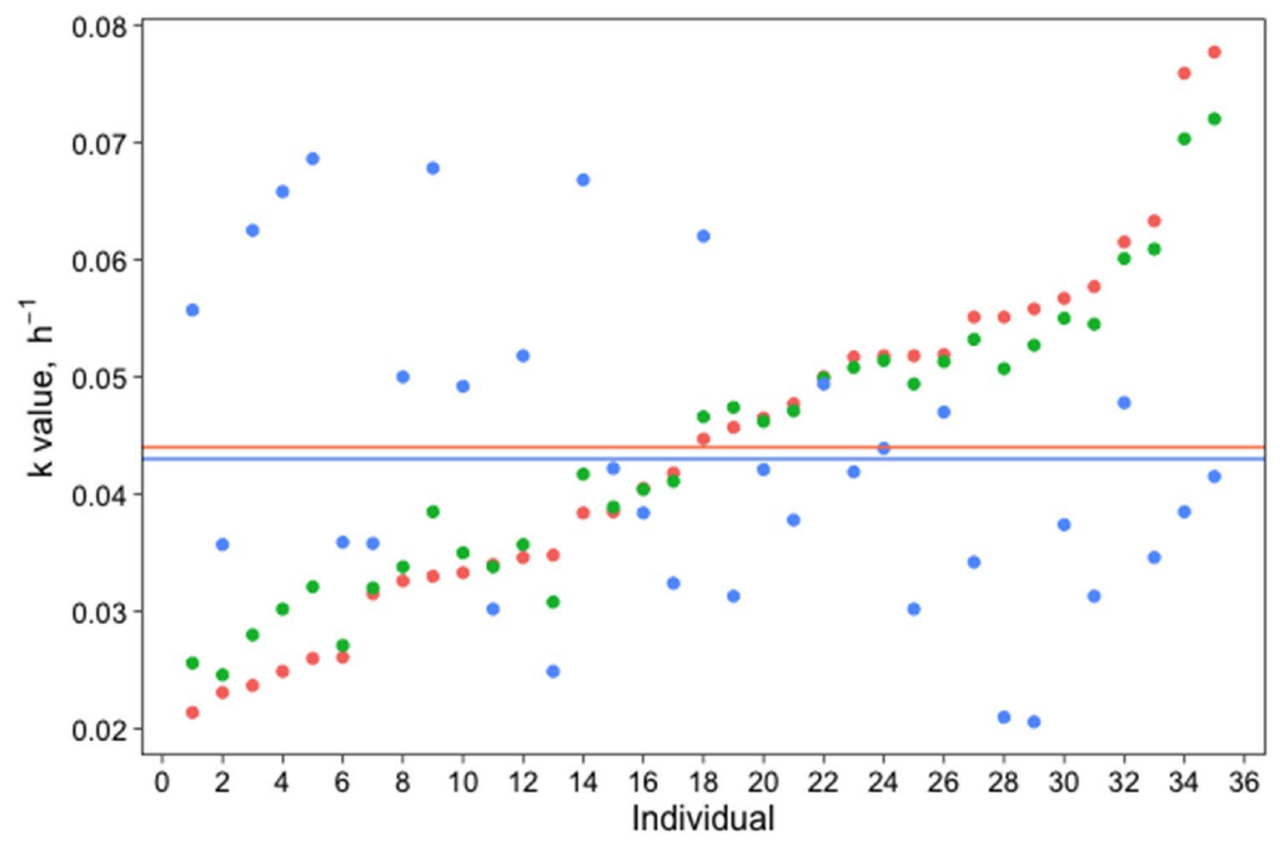

- $k \cdot \mathrm{k}_{\text {in }} \cdot \mathrm{k}_{\text {out }}$

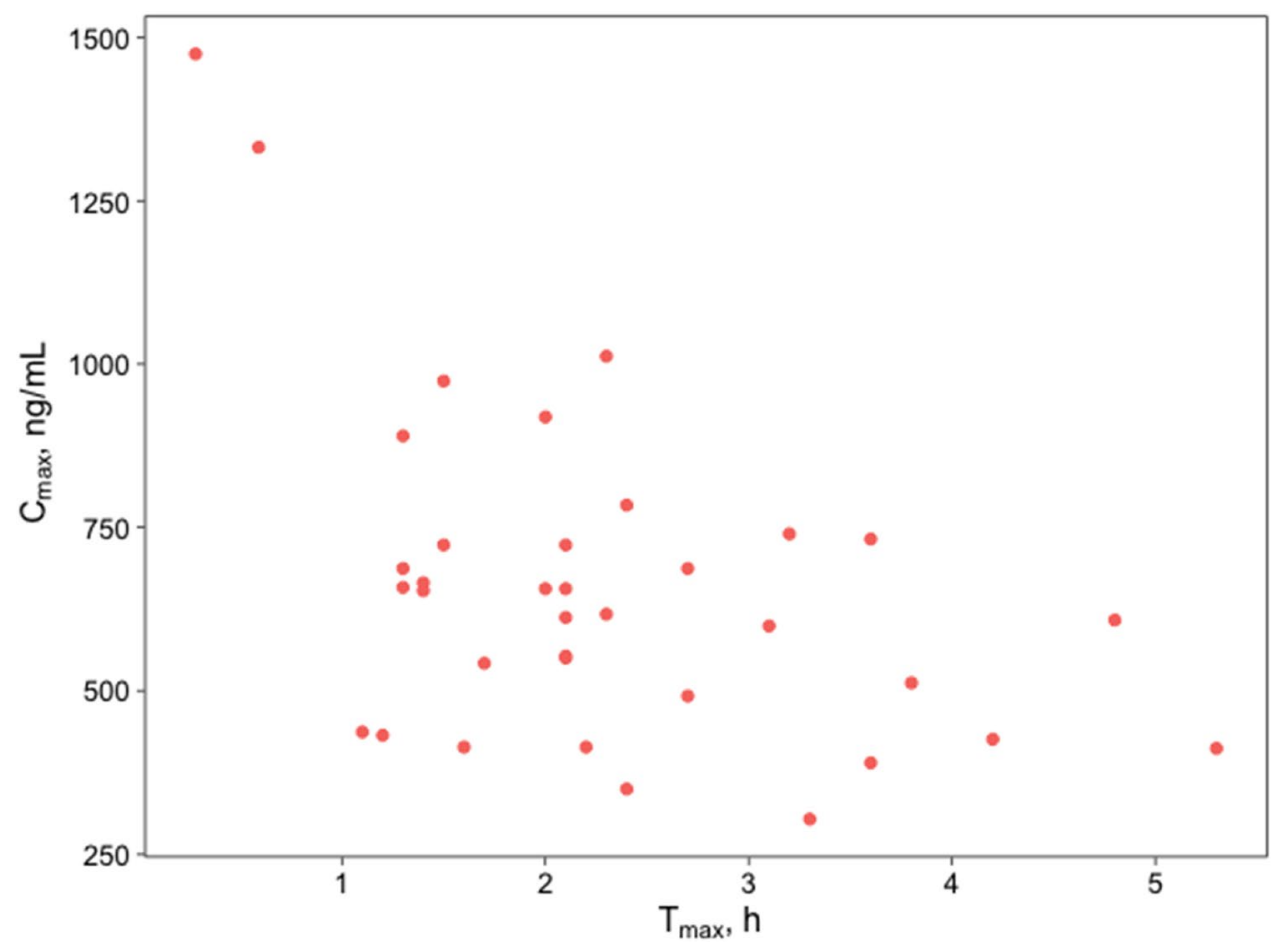

(-0.41), which might be explained by a tendency to satisfy experimental data on the uptake phase of metformin because, in the first $6 \mathrm{~h}$, there were five experimental data points where the MSE was calculated, while there were only two measurements (at 10 and $24 \mathrm{~h}$ ) for the elimination phase.

The $C_{\max }$ and time to reach $C_{\max }\left(T_{\max }\right)$ (Fig. 4) were also very different among individuals, leading to larger differences between the model simulations and experimental 


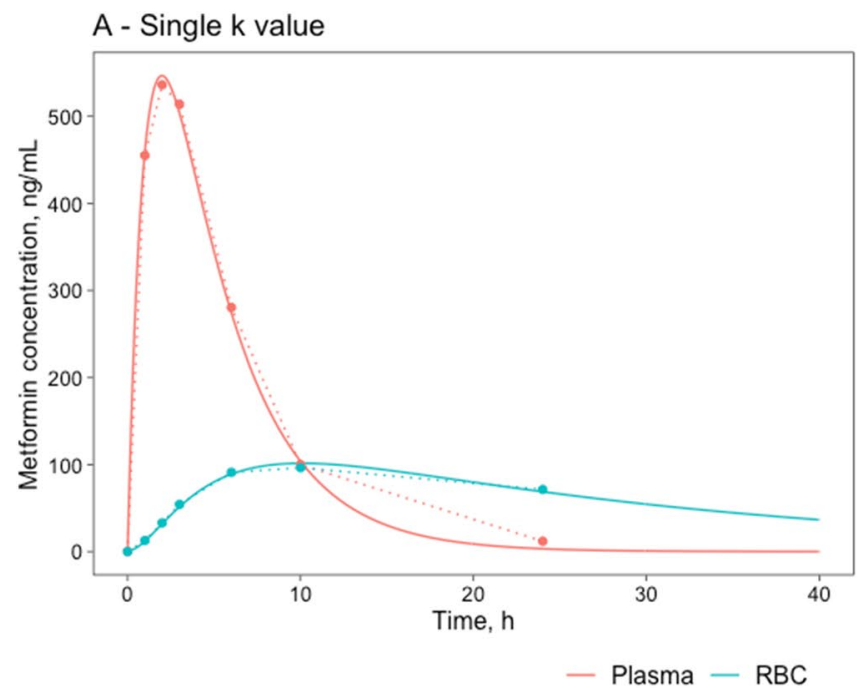

Fig. 5 Parameter estimation results of the best-fit, individual 16. The dots show the experimental values, while the lines represent the model simulation. a Single $k$-value $(k=0.040$, mean

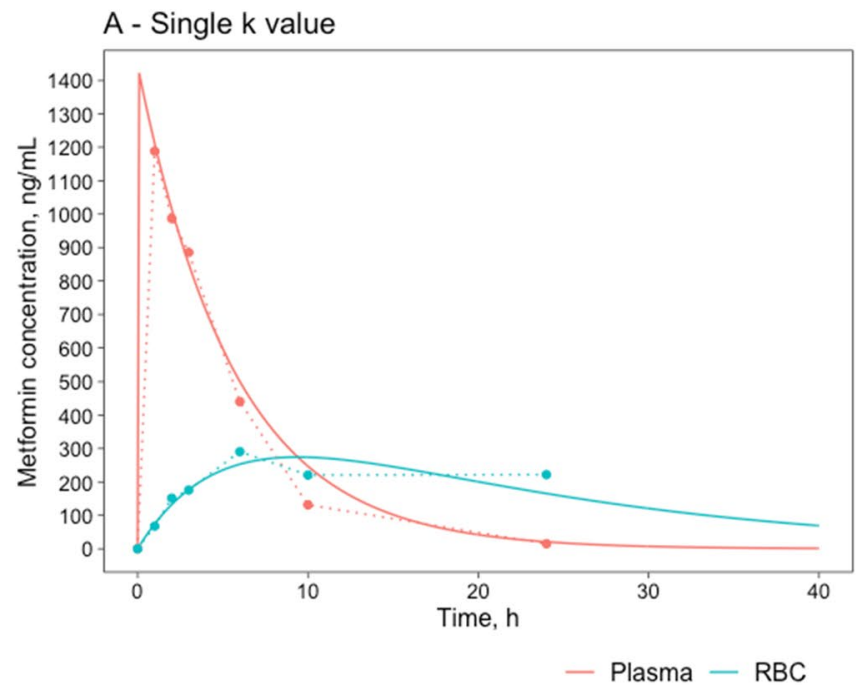

Fig. 6 Parameter estimation results of the worst-fit, individual 31. The dots show the experimental values, while the lines represent model simulation. a Single $k$-value $\left(k=0.058 \mathrm{~h}^{-1}\right.$, mean square

data, expressed as the MSE (see Online Resource 4). A faster $T_{\max }$ correlates with a higher $k$-value. The MSE average value for a single diffusion coefficient $(1522 \pm 1761)$ was larger than the value of independent diffusion coefficients $(1026 \pm 1321)$.

The differences between the best (Fig. 5) and worst (Fig. 6) MSE values for individual experimental data for parameter estimation results were large. The case with the smallest MSE (Fig. 5) demonstrated a very good fit, partly because the experimental results for plasma and RBC data fit the biexponential decline very well; however, it was

\section{$B$ - Independent $\mathrm{k}_{\text {in }} \mathrm{k}_{\text {out }}$ values}

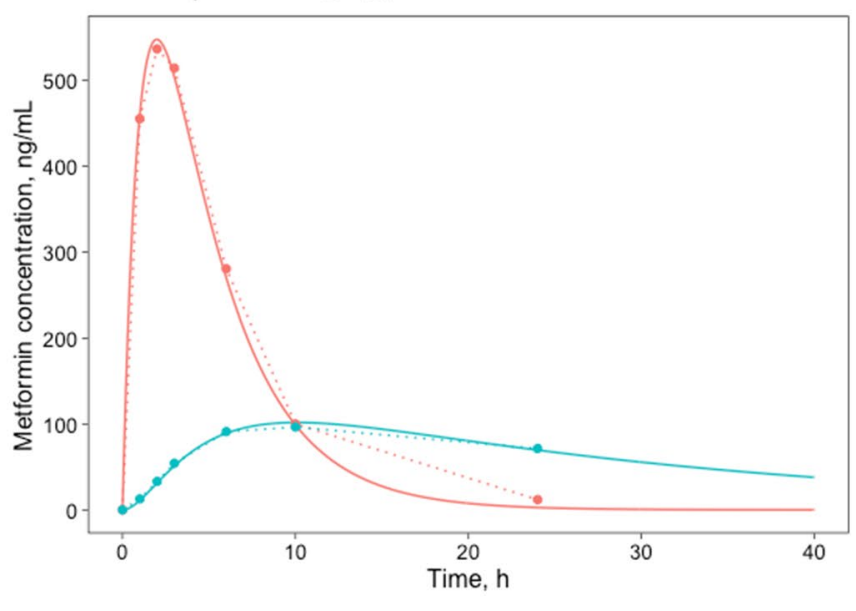

... Measured - Model fit

square error $=67)$; $\mathbf{b}$ different $k_{\text {in }}$ and $k_{\text {out }}$ values $\left(k_{\text {in }}=0.040\right.$ and $k_{\text {out }}=0.038$, mean square error $=65$ )

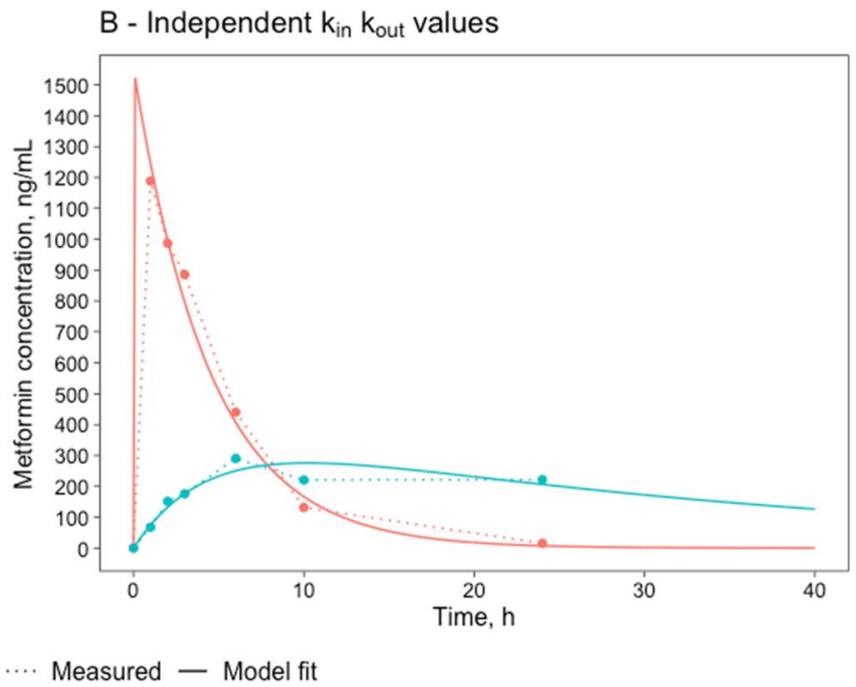

error $=9244) ; \mathbf{b}$ different $k_{\text {in }}$ and $k_{\text {out }}$ values $\left(k_{\text {in }}=0.055 \mathrm{~h}^{-1}\right.$ and $k_{\text {out }}=0.031 \mathrm{~h}^{-1}$, mean square error $=6271$ ).

different for individual No. 31 (Fig. 6), where plasma and $\mathrm{RBC}$ concentrations did not correspond to the expected biexponential curve. In both extreme cases, the model with a single coefficient performed similar (Figs. 5a and 6a) to the model with two independent coefficients (Figs. 5b and $6 b)$.

\subsection{Correlation of Model Parameters}

The correlation between $k, k_{\text {in, }}$ and $k_{\text {out }}$ is described in Sect. 3.1. Correlation of the single diffusion transport rate 
coefficient $(k)$ of tested individuals using other parameters was tested using experimental and modeling results. There was a weak negative correlation of -0.35 with the $T_{\max }$ of metformin concentration in plasma, indicating that individuals with a smaller $T_{\max }$ in plasma are likely to have a larger $k$-value, enabling them to reach maximum concentration faster. No correlation $(-0.071)$ of $\mathrm{k}$ was found with the $C_{\max }$ of metformin concentration in plasma.

When analyzing individual cases of two transport rate coefficients, $k_{\text {in }}$ and $k_{\text {out, }}$ several interesting correlations were found. The low correlation between $k_{\text {in }}$ and $k_{\text {out }}$ of -0.30 agrees with the wide-ranging $k_{\text {in }} / k_{\text {out }}$ ratio. A strong positive correlation (0.67) between $k_{\text {out }}$ and $T_{\max }$ suggests that a later maximum point leads to faster discharge of metformin, enabled by a larger $k_{\text {out }}$. A weak negative correlation $(-0.29)$ was found between $k_{\text {out }}$ and $C_{\max }$, while $\mathrm{k}_{\text {in }}$ had a weaker correlation with both $T_{\max }(-0.26)$ and $C_{\max }(-0.12)$.

The $k_{\text {in }} / k_{\text {out }}$ ratio characterizes the dominance of the $k_{\text {in }}$ coefficient over the $k_{\text {out }}$ coefficient. The ratio equals one if both coefficients are the same, and is larger than 1 if $k_{\text {in }}$ is bigger than $k_{\text {out }}$. The correlation between the $k_{\text {in }} / k_{\text {out }}$ ratio and $T_{\max }$ was -0.51 , indicating that a faster and higher maximum would need larger $k_{\text {in }}$ values relative to $k_{\text {out. }}$ Surprisingly, a low correlation $(0.10)$ had a $k_{\text {in }} / k_{\text {out }}$ ratio with $C_{\max }$.

\section{Discussion}

\subsection{Single versus Independent Diffusion Coefficients}

The current study suggests that a single passive transport rate coefficient is sufficient for the description of metformin exchange between plasma and RBCs, even in the case of large individual variation in the concentration dynamics of metformin in plasma (Fig. 4 and Online Resource 1). The introduction of independent coefficients $\left(k_{\text {in }}\right.$ and $\left.k_{\text {out }}\right)$ does not radically improve the fitness (Figs. 2, 5, and 6). The similarity of the average values of $k_{\text {in }}$ and $k_{\text {out }}\left(0.044 \mathrm{~h}^{-1}\right.$ and $0.043 \mathrm{~h}^{-1}$, respectively) underlines that the transport rate coefficients are the same in both directions despite the wide distribution of $k_{\text {out }}$ (Fig. 3) and low correlation with k. In the case of a smaller number of involved individuals, the average values might not be that close. The very high correlation between $k$ and $k_{\text {in }}$, and weak correlation with $k_{\text {out }}$, might be explained by the fact that five experimental data points were measured in the first $3 \mathrm{~h}$, when the impact of $k_{\text {in }}$ is dominating, and just two data points were measured after $6 \mathrm{~h}$. This stimulates $\mathrm{k}_{\text {in }}$ to be similar to $k$ in determining the correctness of the first data points, leaving $k_{\text {out }}$ to compensate deviations from the experimental data after $6 \mathrm{~h}$, with low correlation to $k$.
The fact that the transport rate is proportional to the concentration, and the same coefficient can be used in both directions, supports the hypothesis that passive transport is the dominant mode of metformin exchange between plasma and $\mathrm{RBC}$, and the influence of active transport processes is negligible because, in the case of active transport, the transport rate coefficients should be (1) nonlinear and (2) stronger in one of the directions. Our research cannot determine if passive transport is carried out by simple diffusion or facilitated diffusion. This is in line with earlier published research suggesting that transport between plasma and RBCs occurs exceptionally via passive transport (diffusion) only as the metformin-specific transporters are not expressed on the RBC surface [4, 8], contradicting alternative assumptions that metformin's hydrophilic nature is not suitable for crossing the lipid bilayer via diffusion [4]. It could be speculated that the unique properties of metformin as a small molecule (165 Da), and the high ionization level at physiological $\mathrm{pH}$, favors its entry and release from the RBCs through concentration-driven mechanisms such as diffusion mechanisms relayed on aqueous channels [33], therefore the permeability of metformin should be equal in both directions [34, 35]. Based on these theoretical assumptions, we could conclude that our results do not contradict the previously established physiochemical properties of metformin and are in line with mentioned theoretical assumptions.

It has been previously observed that the metformin repartitioning rate (we assume that the metformin transport rate is meant here) from RBCs into plasma was two- to even fivefold faster than distribution from plasma into the RBCs $[17,18]$, however the mechanistic process behind this phenomenon has not been provided. In other research, it has been presumed that the $\mathrm{pH}$ difference between plasma and $\mathrm{RBCs}$ could cause the slower repartitioning from RBCs due to the electronegative membrane potential and ion-trapping effect of metformin into the RBC due to its basic properties [36-38], thus challenging the observations described by Xie et al. [18]. In the current study, the use of independent coefficients to describe uptake $\left(k_{\text {in }}\right)$ and release $\left(k_{\text {out }}\right)$ allowed faster uptake or release of metformin but did not improve the fit to experimental data. Therefore, it could be assumed that the in vivo ion-trapping effect has no or negligible effect on metformin repartitioning from the RBCs. According to the model simulations, the proportions between incoming and outgoing metformin transport rates constantly change (Fig. 7). A single transport rate coefficient $\left(k=k_{\text {in }}=k_{\text {out }}\right)$ does not mean the same incoming and outgoing flux of metformin because the influx and outflux (formulas 1 and 2) are proportional to the metformin concentration. As a consequence, the resulting flux is proportional to the concentration difference on both sides of the RBC membrane. The concentration in plasma is greatest immediately after administration of the dose, leading to a much faster influx 

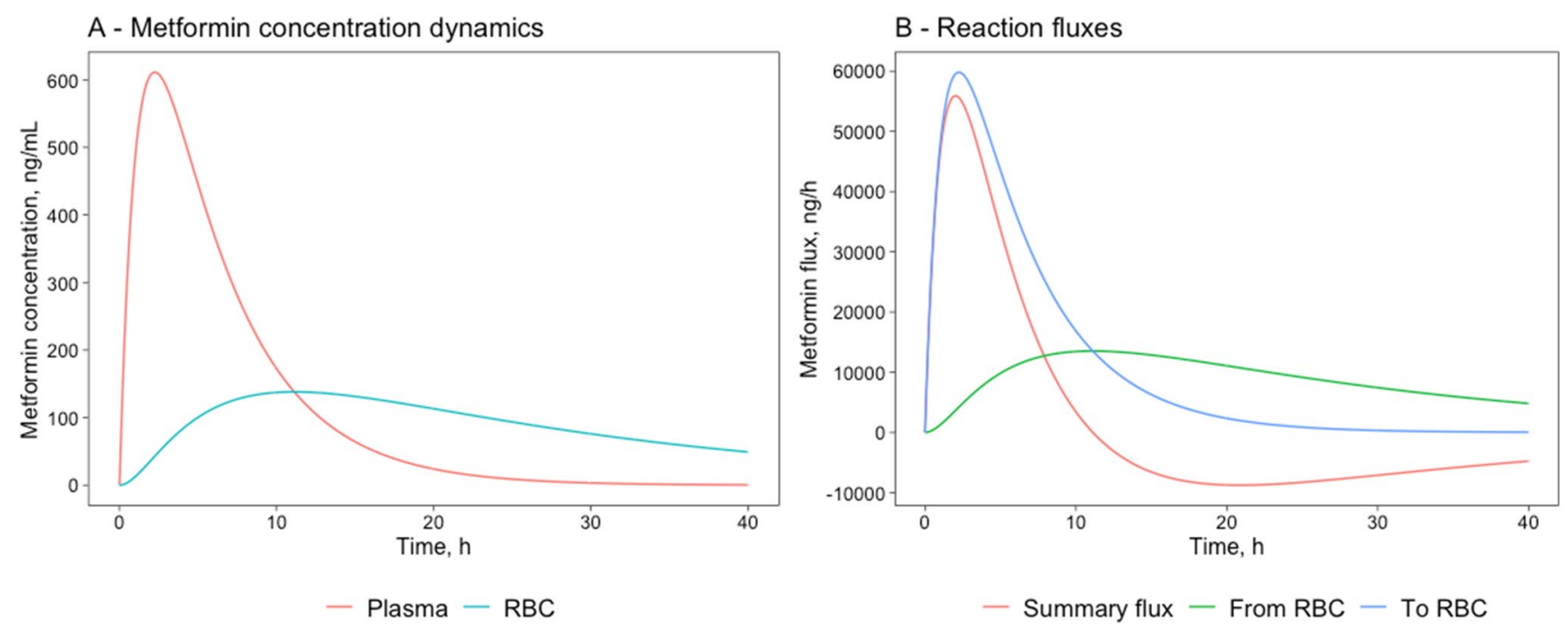

Fig. 7 Dynamics of concentrations in a plasma and RBCs, and $\mathbf{b}$ influx (blue), outflux (red), and summary flux (green) to RBCs in the case of the average curve with a single coefficient. $R B C s$ red blood cells

than outflux at the uptake phase and the opposite at the elimination phase, where plasma concentration is smaller than in RBCs (Fig. 7). Therefore, the statement mentioned earlier regarding the repartitioning rate being two- to fivefold faster [18] is true, starting from about the 12th hour (Fig. 7), and wrong before that time. However, the difference in transport flux rates is due to the difference in concentrations, while the diffusion transport rate coefficient stays the same.

Another interesting aspect of metformin exchange between plasma and RBCs is the contradiction between the involvement of concentrations equalizing passive transport and the fact that in long-term use, the mean concentration values in plasma and RBCs do not become equal as determined experimentally [12] and by mathematical modeling [13]. This contradiction can be explained by the heavy timedependence of the concentration in plasma, leading to very fast metformin transport to RBCs during the first hours after dose administration, followed by long and slow transport from RBCs, both following the concentration gradient. The effects of both processes are not equal, causing differences in the mean values of metformin concentrations in plasma and RBCs.

\subsection{Passive Transport Coefficient Values}

Both the measurement accuracy and approximation accuracy can influence the estimated diffusion coefficient values. The proposed single diffusion transport rate coefficient $k=0.044 \pm 0.014 \mathrm{~h}^{-1}$ can differ between studies to some extent. We have applied our model to published data from other studies.

The dynamics of metformin concentrations in plasma in model simulations are in line with the study by Robert and colleagues, where a single peroral dose of metformin $850 \mathrm{mg}$ was administered, which is similar to that reported in the current study. The concentration ratio switches over in favor of RBCs in a time-dependent manner approximately $8-16 \mathrm{~h}$ after administration $[7,8]$, while in our experimental data and simulations of the average curve, this occurs at $11.5 \mathrm{~h}$. It has been found that the $C_{\max }$ and elimination half-life ( $\left.\mathrm{t}_{1 / 2}\right)$ differ between RBCs and plasma (300 vs. $1700 \mathrm{ng} / \mathrm{mL}$ and 23.4 vs. $2.7 \mathrm{~h}$, respectively) [8], and correspond with our results, where the $C_{\max }$ and $t_{1 / 2}$ in RBCs and plasma for the average curve (Fig. 2) were 140 and $617 \mathrm{ng} / \mathrm{mL}$ and 33 and $7.5 \mathrm{~h}$, respectively. The transport rate coefficient estimated for an average concentration-time curve of a single peroral dose of metformin $850 \mathrm{mg}$ according to Fig. 1 in the study by Robert and colleagues was $0.039 \mathrm{~h}^{-1}$, which is close to the $k$-value reported in this current study.

Lalau et al. [39] reported on the lactic acidosis and extremal metformin accumulation in a patient treated with metformin. Metformin concentrations in the blood reached 130fold concentrations $(80,000 \mathrm{ng} / \mathrm{mL})$ after administration of $850 \mathrm{mg}$ twice daily $[12,39]$, compared with those observed in this current study. The transport rate coefficient estimated in our model was $0.025 \mathrm{~h}^{-1}$, which is within the range of coefficients estimated from individual patients (Fig. 3).

The calculated transport rate coefficient values of $0.044 \pm 0.014 \mathrm{~h}^{-1}$ from our study data, $0.039 \mathrm{~h}^{-1}$ from the data reported by Robert and colleagues [8], and $0.025 \mathrm{~h}^{-1}$ reported by Lalau and Lacroix [12] fall within the values observed among the individuals involved in the current study (Fig. 3). 


\section{Conclusions}

It is possible to describe the partitioning and repartitioning between RBCs and plasma using a single transport rate coefficient, supporting the assumption that diffusion was the main process ensuring metformin transportation between RBCs and plasma. A single transport rate coefficient for both transport directions does not contradict the different metformin transport rates to and from RBCs because the transport rate is proportional to the concentration difference. After dose administration, the metformin concentration in plasma is larger than in RBCs, thus ensuring faster partitioning into RBCs, while, after concentration equilibrium, the concentration in RBCs is higher and repartitioning becomes faster.

Supplementary Information The online version contains supplementary material available at https://doi.org/10.1007/s40262-021-01058-2.

\section{Declarations}

Funding This research was funded by the Latvian Council of Science project "Mathematical model of pharmacokinetics for personalized optimization of metformin therapy" (Grant number: LZP-2018/2-0088). Janis Klovins was supported by the H2020-EU project "Integration of knowledge and biobank resources in comprehensive translational approach for personalized prevention and treatment of metabolic disorders (INTEGROMED)" [Grant agreement ID 857572].

Conflicts of interest Janis Kurlovics, Darta Maija Zake, Linda Zaharenko, Kristaps Berzins, Janis Klovins, and Egils Stalidzans have no conflicts of interest that are directly relevant to the contents of this article.

Author contributions $\mathrm{JKu}, \mathrm{DMZ}, \mathrm{KB}$ and ES participated in the data analysis and interpretation and were involved in the preparation review and approval of this article. $\mathrm{JKu}, \mathrm{KB}$ and $\mathrm{ES}$ developed the structure of the model. LZ and JK1 were involved in the acquisition of data and review and approval of this article.

Open Access This article is licensed under a Creative Commons Attribution-NonCommercial 4.0 International License, which permits any non-commercial use, sharing, adaptation, distribution and reproduction in any medium or format, as long as you give appropriate credit to the original author(s) and the source, provide a link to the Creative Commons licence, and indicate if changes were made. The images or other third party material in this article are included in the article's Creative Commons licence, unless indicated otherwise in a credit line to the material. If material is not included in the article's Creative Commons licence and your intended use is not permitted by statutory regulation or exceeds the permitted use, you will need to obtain permission directly from the copyright holder. To view a copy of this licence, visit http://creativecommons.org/licenses/by-nc/4.0/.

\section{References}

1. Drzewoski J, Hanefeld M. The current and potential therapeutic use of metformin - the good old drug. Pharmaceuticals. 2021;14:122.

2. Graham GG, Punt J, Arora M, Day RO, Doogue MP, Duong JK, et al. Clinical pharmacokinetics of metformin. Clin Pharmacokinet. 2011;50:81-98.

3. Scheen AJ. Clinical pharmacokinetics of metformin. Clin Pharmacokinet. 1996;30:359-71.

4. Liang X, Giacomini KM. Transporters involved in metformin pharmacokinetics and treatment response. J Pharm Sci. 2017; 106:2245-50.

5. Martin D, Az Eddine T, Mohammed A, Attari Ahmed E, Youssef K, Farida A. Determination of concentration intra-erythrocyte of metformin in type 2 diabetic patients with or without renal impairment: comparative study of concentrations intra-erythrocytes between two groups of diabetic patients. IOSR J Pharm. 2015;5:50-6.

6. Pentikäinen PJ, Neuvonen PJ, Penttilä A. Pharmacokinetics of metformin after intravenous and oral administration to man. Eur J Clin Pharmacol. 1979;16:195-202.

7. Tucker G, Casey C, Phillips P, Connor H, Ward J, Woods H. Metformin kinetics in healthy subjects and in patients with diabetes mellitus. Br J Clin Pharmacol. 1981;12:235-46.

8. Robert F, Fendri S, Hary L, Lacroix C, Andréjak M, Lalau JD. Kinetics of plasma and erythrocyte metformin after acute administration in healthy subjects. Diabetes Metab. 2003;29:279-83.

9. Paleari L, Burhenne J, Weiss J, Foersch S, Roth W, Parodi A, et al. High accumulation of metformin in colonic tissue of subjects with diabetes or the metabolic syndrome. Gastroenterology. 2018;154:1543-5.

10. Wilcock C, Bailey CJ. Accumulation of metformin by tissues of the normal and diabetic mouse. Xenobiotica. 1994;24:49-57.

11. Detaille D, Guigas B, Leverve X, Wiernsperger N, Devos P. Obligatory role of membrane events in the regulatory effect of metformin on the respiratory chain function. Biochem Pharmacol. 2002;63:1259-72.

12. Lalau JD, Lacroix C. Measurement of metformin concentration in erythrocytes: Clinical implications. Diabetes Obes Metab. 2003;5:93-8.

13. Zake DM, Kurlovics J, Zaharenko L, Komasilovs V, Klovins J, Stalidzans E. Physiologically based metformin pharmacokinetics model of mice and scale-up to humans for the estimation of concentrations in various tissues. Lampe JN, editor. PLoS ONE. 2021;16:594.

14. Hanke N, Türk D, Selzer D, Ishiguro N, Ebner T, Wiebe S, et al. A comprehensive whole-body physiologically based pharmacokinetic drug-drug-gene interaction model of metformin and cimetidine in healthy adults and renally impaired individuals. Clin Pharmacokinet. 2020;59:1419-31.

15. Nishiyama $\mathrm{K}$, Toshimoto $\mathrm{K}$, Lee $\mathrm{W}$, Ishiguro $\mathrm{N}$, Bister $\mathrm{B}$, Sugiyama Y. Physiologically-based pharmacokinetic modeling analysis for quantitative prediction of renal transporter-mediated interactions between metformin and cimetidine. CPT Pharmacometrics Syst Pharmacol. 2019;8:396-406.

16. Wiernsperger NF, Bailey CJ. The antihyperglycaemic effect of metformin. Drugs. 1999;58:31-9.

17. Noel M. Kinetic study of normal and sustained release dosage forms of metformin in normal subjects. J Int Biomed Inf Data. 1980;1:9-20.

18. Xie F, Ke AB, Bowers GD, Zamek-Gliszczynski MJ. Metformin's intrinsic blood-to-plasma partition ratio (B/P): Reconciling the perceived high in vivo $\mathrm{B} / \mathrm{P}>10$ with the in vitro equilibrium value of unity. J Pharmacol Exp Ther. 2015;354:225-9. 
19. Stalidzans E, Zanin M, Tieri P, Castiglione F, Polster A, Scheiner S, et al. Mechanistic modeling and multiscale applications for precision medicine: theory and practice. Netw Syst Med. 2020;3:36-56.

20. Zaharenko L. Pharmacogenetics of efficiency and tolerance of the peroral antidiabetic drug metformin [doctoral thesis]. Latvijas Universitāte; 2015. http://dspace.lu.lv/dspace/handle/7/31319.

21. Tarasova L, Kalnina I, Geldnere K, Bumbure A, Ritenberga R, Nikitina-Zake L, et al. Association of genetic variation in the organic cation transporters OCT1, OCT2 and multidrug and toxin extrusion 1 transporter protein genes with the gastrointestinal side effects and lower BMI in metformin-treated type 2 diabetes patients. Pharmacogenet Genom. 2012;22:659-66.

22. Zaharenko L, Kalnina I, Geldnere K, Konrade I, Grinberga S, Židzik J, et al. Single nucleotide polymorphisms in the intergenic region between metformin transporter OCT2 and OCT3 coding genes are associated with short-Term response to metformin monotherapy in type 2 diabetes mellitus patients. Eur J Endocrinol. 2016;175:531-40.

23. Yeagle PL. The membranes of cells. 3rd ed. Elsevier Inc.; 2016. p. 335-78.

24. Belpaire FM, Bogaert MG. The fate of xenobiotics in living organisms. In: Wermuth $\mathrm{C}$, editor. The practice of medicinal chemistry. 2nd ed. Elsevier Inc.; 2003. p. 501-15.

25. Enderle JD. Compartmental modeling. In: Enderle JD, Bronzino $\mathrm{J}$, Blanchard S, editors. Introduction to biomedical engineering. Elsevier Inc.; 2011. p. 359-445.

26. Flynn E. Pharmacokinetic compartmental modeling. In: Enna SJ, Bylund DB, editors. xPharm: the comprehensive pharmacology reference. Elsevier Inc.; 2007. p. 1-5.

27. Seabury RW, Stork CM. Pharmacokinetic and Toxicokinetic Modeling. In: Wexler P (ed). Encyclopedia of toxicology. Third Ed. Elsevier Inc.; 2014. p. 856-61. https://linkinghub.elsevier.com/ retrieve/pii/B9780123864543007661.

28. Davies B, Morris T. Physiological parameters in laboratory animals and humans. Pharm Res. 1993;10:1093-5.
29. Hoops S, Gauges R, Lee C, Pahle J, Simus N, Singhal M, et al. COPASI-a COmplex PAthway SImulator. Bioinformatics. 2006;22:3067-74.

30. Kostromins A, Mozga I, Stalidzans E. ConvAn: a convergence analyzing tool for optimization of biochemical networks. BioSystems. 2012;108:73-7.

31. Elsts A, Pentjuss A, Stalidzans E. SpaceScanner: COPASI wrapper for automated management of global stochastic optimization experiments. Bioinformatics. 2017;33:2966-7.

32. Malik-Sheriff RS, Glont M, Nguyen TVN, Tiwari K, Roberts MG, Xavier A, et al. BioModels-15 years of sharing computational models in life science. Nucleic Acids Res. 2020;48:D407-15.

33. Hinderling PH. Red blood cells: a neglected compartment in pharmacokinetics and pharmacodynamics. Pharmacol Rev. 1997;49:279-95.

34. Kalvass JC, Pollack GM. Kinetic considerations for the quantitative assessment of efflux activity and inhibition: implications for understanding and predicting the effects of efflux inhibition. Pharm Res. 2007;24:265-76.

35. Zamek-Gliszczynski MJ, Lee CA, Poirier A, Bentz J, Chu X, Ellens H, et al. ITC recommendations for transporter kinetic parameter estimation and translational modeling of transportmediated PK and DDIs in humans. Clin Pharmacol Ther. 2013;94:64-79.

36. Peura L, Huttunen KM. Sustained release of metformin via red blood cell accumulated sulfenamide prodrug. J Pharm Sci. 2014;103:2207-10.

37. Gong L, Goswami S, Giacomini KM, Altman RB, Klein TE. Metformin pathways: pharmacokinetics and pharmacodynamics. Pharmacogenet Genomics. 2012;22:820-7.

38. Rodgers T, Leahy D, Rowland M. Physiologically based pharmacokinetic modeling 1: Predicting the tissue distribution of moderate-to-strong bases. J Pharm Sci. 2005;94:1259-76.

39. Lalau JD, Race JM, Brinquin L. Lactic acidosis in metformin therapy: relationship between plasma metformin concentration and renal function. Diabetes Care. 1998;21(8):1366-7. 